\title{
Nurses' Perceptions of Patient Safety Culture at King Khaled University Hospital, Saudi Arabia
}

\author{
Prof. Mohammed S. Al-Amri \\ Department of Management \\ College of Business Administration \\ King Saud University, Riyadh, Saudi Arabia
}

\author{
Mazin S. ALMendeil \\ Saudi Food \\ and Drug Authority \\ Riyadh, Saudi Arabia
}

\begin{abstract}
The aim of this study is to assess the perception of nurses towards patient safety culture at King Khalid University Hospital (KKUH) in Saudi Arabia. To achieve this aim, the study utilized a questionnaire developed by the Hospital Survey On Patient Safety Culture (HSOPSC) (2008) and includes (34) items that measures patient safety culture on the patient safety culture dimensions. This questionnaire has been distributed to a sample consists of (250) nurses. A total of (199) complete questionnaires has been received back at a response rate of (80\%). After analyzing data and testing questions, the study revealed: (1) the dimension of highest positively is teamwork within units (2) the dimension of lowest positively is hospital hands-off and transitions (3) the study revealed that there are statistically significant differences in the response of the respondents on the differences between the nurses perception of patient safety culture due to some personal characteristics (age, educational qualification, and years of experience) and (4) the study found that (64\%) of the study sample indicated the absence of any reports on medical errors. Based on these results, certain recommendations were suggested.
\end{abstract}

Keywords: Patient Safety Culture, King Khalid University Hospital, Saudi Arabia.

\section{Introduction}

The Institute of Medicine (IOM, 2004) addressed safety culture, as an important concept in providing a safe environment for employees and patients. It is product of individual and group values, attitudes, competencies, and patterns of behavior that determine the commitment to, and the style and proficiency of, an organization's health and safety programs. Furthermore, the report stated that errors can be prevented by designing systems that make it hard for people to do the wrong thing and easy for people to do the right thing.

The Agency for Healthcare Research and Quality (AHRQ), has indicated many factors that influence patient safety culture, e.g. managers' actions and support and health care staff characteristics. Teamwork as well as the organization's ability to learn and improve is also important. Several studies have been conducted regarding patient safety culture as perceived by different health care staff, and differences between groups have also been reported.

When improving safety, measuring patient safety culture is of great importance. Examining health care staff's perception of patient safety culture and aspects influencing patient safety culture represents the first step when managers want to improve health care quality and safety.

\footnotetext{
* This article was submitted in December 2017, and accepted for publishing in May 2018, Published: September 2020. The researchers thank the deanship of scientific research at King Saud University represented by the College of Business Administration Research Center for the financial support of this research.

(c) Arab Administrative Development Organization- League of Arab States, 2020, pp 283-300،

DOI: 10.21608/aja.2020.111867
} 
In Saudi Arabia, medical errors and adverse events have been subjected to increasing media attention and public concern. As a result, the number of legal cases related to medical errors in Saudi Arabia has increased from 896 cases in 2005 to 1356 cases in 2008, an increase of 51.3\%. Policy makers and health organizations continually strive to reduce medical errors and improve quality of health care. Several initiatives have been implemented to create a culture of safety mainly through establishing standards and initiating accreditation schemes. (Alahmadi, 2010)

This study assessed nurses' perceptions of the safety culture in units at King Khaled University Hospital and to identify factors that influence the levels of frequency of events reported.

\section{The problem of the study}

Observers of the professional safety and health situation in medical institutions cannot fail to notice the grave and serious violations of the professional safety code in these institutions. The absence of, and negligence in applying safety code in many hospital cannot go unnoticed, especially that such negligence has claimed the lives of some patients and left others with permanent disabilities (such as: total loss of vision in one eye, blindness and low vision, hearing loss and deafness, coma, loss of one or both of arms, loss of one or both legs) that resulted from medical errors while performing work duties. Such injuries and disabilities are a natural outcome of working in environments which lack the minimum requirements of safety and protection.

A medical expert has addressed the rate of such errors when he stated that «accurate statistics on the number of medical errors occurring in the Kingdom, and the region at large, are unavailable due to the absence of monitoring. Admitting mistakes is an ethical necessity and may help prevent such mistakes from recurring in the future». He also said that «it is not easy to judge errors occurring in the medical field due to their complexity. The medical errors in obstetrics and gynecology account for $27 \%$ of the total number of errors on record, the largest percentage in any specialty. Surgical errors account for $17 \%$ of errors, while errors in internal medicine account for $13 \%$ of all cases and pediatrics 10\%» (Irfan, 2016).

Based on the above, the discussion problem can be stated as follows: what are nurses' perception of patient safety culture in King Khalid University Hospital?

\section{The questions of the study}

The main question of this study is: what are nurses' perception of patient safety culture in King Khalid University Hospital? Under this main question, there are a variety of sub-questions:

- What are the nurses' overall perceptions of patient safety culture in KKUH?

- Is there a significant differences between the nurses' perception of patient safety culture and demographic characteristics in KKUH?

- How many event reports the nurses have filled out and submitted in the last year in KKUH?

\section{Research objectives}

The researchers aim to explore the following:

- Nurses' overall perceptions of patient safety culture in KKUH.

- The significant differences between the nurses' perception of patient safety culture and demographic characteristics in $\mathrm{KKUH}$.

- The number of event reports that the nurses have filled out and submitted in the last year in KKUH.

\section{The purposes of the study}

The findings of this study may contribute to more improvement of the patient safety in King Khalid University Hospital. Due to the lack of studies in this field, the recommendations of this study may be a stimulus for researchers to focus their future researches on this vital area. 


\section{Conceptual definitions of terms}

- Culture is the «culture consists of the shared norms, values, and practices associated with a nation, organization, or profession.» (Helmreich, 2000).

- Human Errors are the failure of planned actions to achieve their desired ends without the intervention of some unforeseeable event (Reason, 2000).

- Errors are the failure of a planned action to be completed as intended. Errors may also be the use of a wrong plan to achieve an aim (Reason, 2000)

- Patient safety is the avoidance, prevention and amelioration of adverse outcomes or injuries stemming from the process of health care (IOM, 2004).

- Safety culture is the product of individual and group values, attitudes, competencies, and patterns of behavior that determine the commitment to, and the style and proficiency of, an organization's health and safety management and programs. Organizations with a positive safety culture are characterized by communications founded on mutual trust, by shared perceptions of the importance of safety, and by confidence in the efficacy of preventative measures (ACSNI Study Group on Human Factors, 1993).

Based on the previous definitions, the researchers were able to define the culture of patient safety as procedures carried out by the hospital - private or public - to deal with the patient and protect him/her from being exposed to any physical or psychological harm or risks he might be subjected to while receiving medical care from the hospital.

\section{Literature review}

\section{Theoretical framework}

Cooper used Bandura's Model of Reciprocal Determinism (Bandura, 1978) to explain safety culture. The model contains three elements including person (internal psychological factors), and behavior and situation (external observable factors) (Figure 1). The Model of Reciprocal Determinism (RD) explains the interactions between the three elements and how they influence one another. The model also demonstrates that people are neither deterministically controlled by their environments nor entirely self-determining. Bandura proposed that behavior and personality are shaped by the interaction between cognitive factors and environmental factors.

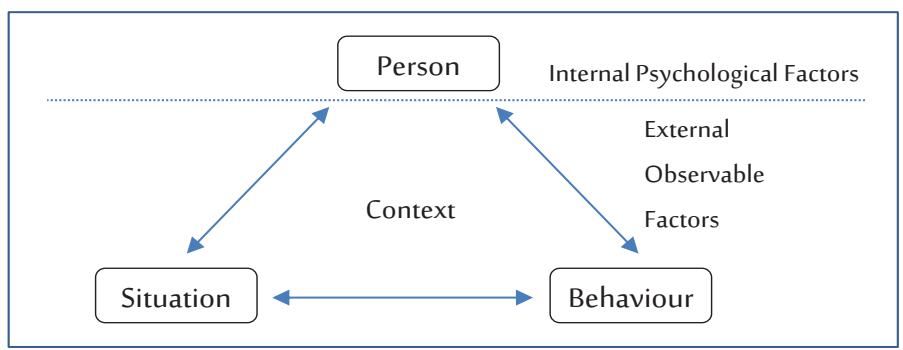

Figure 1: Model of Reciprocal Determinism from Bandura (1978)

Developed the Reciprocal Safety Culture Model [RSCM]. Cooper noted there are three major elements of safety culture consistent with Bandura's RD Model (Bandura, 1978). Person represents the psychological components aligned with intrinsic cultural elements of values, beliefs and assumptions. Behaviors and situations align with extrinsic elements of norms, rituals, and symbols that make up the safety behaviors of workers and management. The model (figure 2) is multi layered with person, job and organization being represented by three main measurable dimensions of safety climate (a substitute measure for safety culture), safety behavior, and safety management system (Cooper, 2000). 


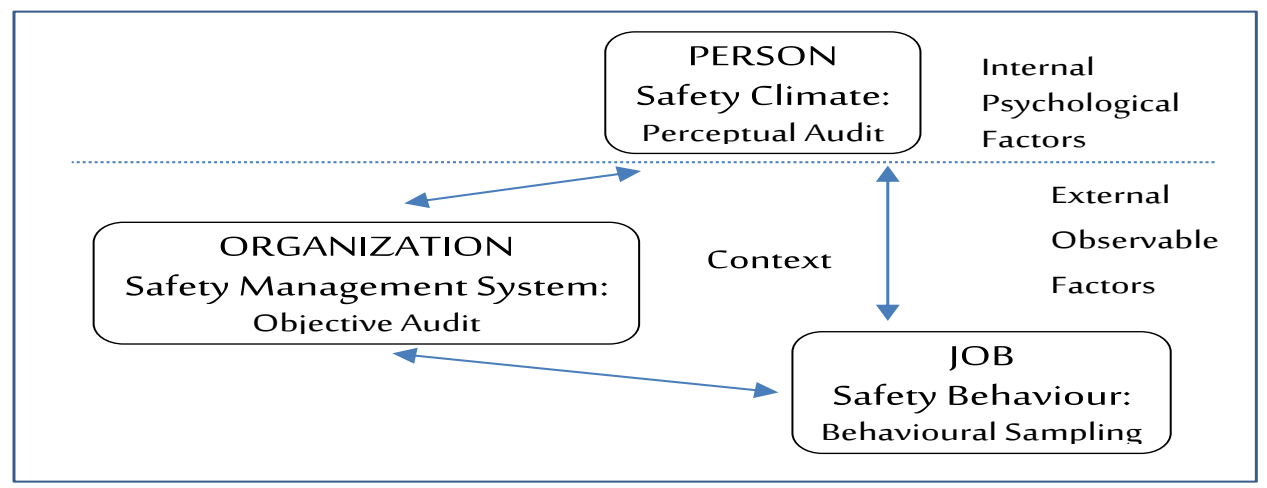

Figure 2: Reciprocal safety culture model from cooper (2000)

Advantages of Bandura's model (1978) reside in the fact that organizations can readily monitor, measure and analyze psychological, behavioral and situational factors. For example, factors such as attitudes and perceptions are represented as the internal psychological factors in an organization and can be accessed via safety culture questionnaires. Ongoing safety-related behavior can be accessed via observation checklists developed as a part of behavior safety initiatives. Organizational factors can be accessed via safety management system audits (Cooper, 2000).

\section{Measuring safety culture}

This can be achieved by:

a- Observation behavior is one of the three major dimensions of Coopers Reciprocal Safety Culture Model (Fig.2), and can be measured through observation. Some organizations have introduced Behavior-Based Safety (BBS) methods in an effort to reduce work-related incidents and accidents.

b- Safety audits are useful to measure whether organizations policies and procedures are being followed and how they might be improved. Moreover, audit tools provide the organization with feedback which helps the organization to maintain, reinforce and develop its ability to manage and reduce risks. The auditing process involves: collecting information about the health and safety management system, and judging whether it is adequate. (Kennedy, 1998)

c- Survey questionnaire is one of the most popular methods for achieving an initial snapshot of safety culture. The goal is to understand the beliefs, assumptions and values which result from the questionnaire. (Zohar, 1980) was the first to measure what he termed a climate for safety in 400 subjects from four different types of organizations. He developed an eight dimensional model which included the importance of safety training; management attitudes towards safety; effects of safe conduct on promotion; level of risk at the work place; effects of required work pace on safety; status of safety officer; effects of safe conduct on social status; and status of the safety committee(Cooper, 2000).

\section{Previous studies}

In a study aimed at evaluating the extent to which the culture supports patient safety, conducted by Alahmadi (2010) on a group of (223) health professionals, including nurses, technicians, managers and medical staff at Saudi hospitals, it was found that the dimension of highest positively is organizational learning and continuous improvement, and the dimension of lowest positively is underreporting of events.

A study on the nurses of king Fahad Medical City of Saudi conducted by Aboshaiqah (2010) with a purpose to study the effect of the factors that have on nurses' participation in the patient safety culture found that the dimension of highest positively is hospital management support for the patient safety culture, while the dimension of lowest positively is hospital hands-off and transitions. 
In a study conducted by Aljabri (2012) on a group of two hospitals in the eastern region of Saudi Arabia with an objective to conduct a baseline assessment of the patient safety culture found that the dimension of highest positively is organizational learning and continuous improvement, and the dimension of lowest positively is non-punitive response to error.

A study was done by Mikušová et al. (2012) to find out how healthcare workers perceive patient safety in their organization and how they assess safety culture in individual units at three hospitals from Trnava region. Participants of the study are the total number of respondents included 1787 hospital staff. The results revealed that patient safety in Trnava regional hospitals was evaluated as positive by $50 \%$ of healthcare workers. The highest scores were obtained in specific dimensions as overall perception of safety (74\%) and handoffs and transition (70\%). Additionally, health care workers considered teamwork across hospital units (35\%) and hospital management support for patient safety issues (39\%) as being weak areas, from their perspective.

With an objective to examine similarities and differences in hospital patient safety culture, a study was conducted by Wagner et al., (2013) on a group from the Netherlands, the USA and Taiwan. 45 hospitals in the Netherlands, 622 in the USA and 74 in Taiwan found that on the whole, US respondents were more positive about the safety culture in their hospitals than Dutch and Taiwanese respondents.

In a study organized by Alkorashy (2013) aimed at exploring the factors shaping patient safety management in the Middle East hospitals from the nurses' perspective found that patient safety management efforts in the Middle East hospitals are still in infancy stage.

On a group of (125) healthcare staff, including physicians, nurses, and health officers in general surgery department, faculty of medicine, Trakya University, Edirne-Turkey, a study was conducted by Sagiroglu et al., (2013) who found that the dimension of highest positivity is staffing and the dimension of lowest positively is teamwork within units.

In a study aimed at assessing the awareness of primary healthcare staff members about patient safety culture conducted by (Ghobashi et al., 2014) on a group of (369) healthcare staff members in four primary healthcare centers in Kuwait found that the dimension of highest positivity is teamwork within the center's units and the dimension of lowest positivity is non-punitive response to errors.

A study of nine different types of primary care in the Netherlands conducted by Verbakel et al., (2014) with a purpose to explore perceptions of safety culture found that patient safety culture in Dutch primary care professions on average is perceived positively.

In a study conducted by Al- Doweri et al., (2015) with an objective to review the literature on patient safety culture in terms and applications found that the patient safety culture is approached from different dimensions which are taken into consideration by hospital staff.

In a study conducted by Eldeeb et al., (2016) with an objective to investigate perception of patient safety on a group of (114) nurses at Shebin ElKom Teaching Hospital found that there was significant difference in the nurses' perception of work environment.

A new study carried out by (Zhao et al., 2017) with an objective to identify and qualitatively describe, in a literature review, how the instruments were used to evaluate patient safety culture in the operating rooms and published studies. The authors identified 1025 references, of which 99 were obtained for fulltext assessment; 47 of these studies were deemed relevant and included in the literature review. Most of the studies were from the USA. The most commonly used patient safety culture instrument was Safety Attitude Questionnaire. All identified instruments were used after 2002 and across many fields. Most included studies on patient safety culture were conducted in teaching hospitals or university hospitals. The study pop- 
ulation in the cross-sectional studies was much more than that in the before-after studies. The time span between baseline and follow-up phase of before-after studies were almost over three months.

What distinguishes this study from previous studies is that it deals deal with KKUH, Saudi Banks, which to the best of the researcher knowledge have not been investigated.

\section{Study methodology}

This study used descriptive and analytical study design. Specifically, the researchers collected the necessary data and information that will be used in the entire study. Primary and secondary data were used for the current study. Primary data were collected through questionnaire. Secondary data (theoretical feedback and previous studies) were collected through different sources of books, scientific journals, and the internet. In more details, in this section the authors outline the study approach, the study process, the selection of the sample, measuring instruments, validity of the study, reliability, statistical methods used, limitations of the study, and ethical considerations.

\section{Study approach}

This study includes quantitative techniques. Quantitative study techniques employ numerical data and use statistical analysis to arrive at valuable conclusions.

\section{Study process}

The researchers came in touch with participants and asked them to participate in the study after explaining the nature and the scope of the study.

\section{Population and sampling technique}

The unit analysis is individual level. Table 1. shows that the population of this study consist of all nurses at King Khalid University Hospital. The number of nurses was obtained from the human resource department in the hospital. Currently, the number of nurses of the hospital are as follows:

Table 1

The number of nurses at King Khalid University Hospital

\begin{tabular}{ccc}
\hline Clinics & Population & Sample \\
\hline Wards & 700 & 79 \\
\hline Intensive Care Unit & 80 & 21 \\
\hline Neonatal Intensive Care Unit & 40 & 61 \\
\hline Emergency Room & 70 & 13 \\
\hline Other Clinics & 1100 & 14 \\
\hline Total & 1990 & 199 \\
\hline
\end{tabular}

Out of this number, a total of (199) nurses are selected at random using simple random sampling to represent the nurses of the hospital.

\section{Study instrument}

Data was collected by means of a questionnaire designed by the researchers. It consisted of (34) items, which were designed according to (likert scale): strongly disagree, disagree, neither, agree, strongly agree, and given the weights $(1,2,3,4$, and 5). The higher the mean, indicates higher degree of consent on the item. As the questionnaire was divided into three parts as follows:

- Part One: it included a number of items that aim to know the personal data of the sample members (4 items), they are: gender, age, years of experience and educational qualification.

- Part Two: it included a number of items that aim to measure the patient safety culture dimensions from the perspective of the sample members ( 32 items). These items have been divided into a set of items, namely: teamwork within units: measured by items (1-3), teamwork across units: measured by items (4-5), manager expectations and actions promoting patient safety: measured by items (68), organizational learning and continuous improvement: measured by items (9-10), management support for patient safety: measured by items (11-13), feedback and communication of error: measured by items (14-15), communication openness: measured by items (16-18), frequency of events 
reported: measured by items (19-21), staffing: measured by items (22-24), handoffs and transitions: measured by items (25-27), non-punitive response to errors: measured by items (28-29), overall perception of patient safety: measured by items (30-32). The (32) items were taken from the Hospital Survey on Patient Safety Culture (HSOPSC) developed by the Agency of Healthcare Research and Quality (AHRQ).

- Part Three: it included two items that aim to measure both the overall patient safety and event report from the perspective of the sample members.

\section{Validity of the study}

To testify the validity of the study, a number of steps were taken: First: a number of questionnaires were distributed to a number of referees, professors and specialists in patient safety culture to assess the accuracy of questions. Based on their recommendations and comments, many modifications were done; some items were deleted, new items were added and other items were rephrased until the questionnaire reached its final form. Second: the statistician reviewed the questionnaire in terms of its format, layout, and whether the type of questions were suitable for statistical analysis. Third: a pilot study with thirty participants was conducted to further ensure the validity and reliability of the questionnaire. The following is an explanation of the validity of internal consistency.

First: Pearson correlation coefficients between the items of the survey and between the total score of the dimensions that belong to it:

Table 2: The correlation coefficients between the items of survey and between the total score of the dimensions that belong to it

\begin{tabular}{|c|c|c|c|c|c|c|}
\hline The dimensions & No. & $\begin{array}{c}\text { The } \\
\text { correlation } \\
\text { coefficient }\end{array}$ & No. & $\begin{array}{c}\text { The } \\
\text { correlation } \\
\text { coefficient }\end{array}$ & No. & $\begin{array}{c}\text { The } \\
\text { correlation } \\
\text { coefficient }\end{array}$ \\
\hline Teamwork Within Units & 1 & $0.8824 * *$ & 2 & $0.8264 * *$ & 3 & $0.8601^{* *}$ \\
\hline Teamwork Across Units & 4 & $0.3377^{* *}$ & 5 & $0.8046 * *$ & & \\
\hline Manager's Expectations Actions Promoting Patient Safety & 6 & $0.6725^{* *}$ & 7 & $0.6753^{* *}$ & 8 & $0.5717^{* *}$ \\
\hline Organizational Learning Continuous Improvement & 9 & $0.8788 * *$ & 10 & $0.7722 * *$ & & \\
\hline Management Support for Patient Safety & 11 & $0.6830 * *$ & 12 & $0.6783^{* *}$ & 13 & $0.5511^{* *}$ \\
\hline Feedback \& Communication of Error & 14 & $0.8936^{* *}$ & 15 & $0.8234^{* *}$ & & \\
\hline Communication Openness & 16 & $0.6726^{* *}$ & 17 & $0.7203^{* *}$ & 18 & $0.2574^{* *}$ \\
\hline Frequency of Events Reported & 19 & $0.8879 * *$ & 20 & $0.9031^{* *}$ & 21 & $0.8883^{* *}$ \\
\hline Staffing & 22 & $0.2245^{* *}$ & 23 & $0.7450^{* *}$ & 24 & $0.7198^{* *}$ \\
\hline Handoffs \& Transitions & 25 & $0.8527^{* *}$ & 26 & $0.8660^{* *}$ & 27 & $0.9006^{* *}$ \\
\hline Non-punitive Response to Errors & 28 & $0.9582^{* *}$ & 29 & $0.9609 * *$ & & \\
\hline Overall Perceptions of Patient Safety & 30 & $0.5097^{* *}$ & 31 & $0.5581^{* *}$ & 32 & $0.5591^{* *}$ \\
\hline
\end{tabular}

Second: Pearson correlation coefficients between the items of the survey with the total score of the survey:

Table 3: The correlation coefficients between the items of the survey with the total score of the survey

\begin{tabular}{|c|c|c|c|c|c|c|c|c|c|c|c|c|c|c|c|}
\hline No. & $\begin{array}{l}\text { The } \\
\text { correlation } \\
\text { coefficient }\end{array}$ & No. & $\begin{array}{l}\text { The } \\
\text { correlation } \\
\text { coefficient }\end{array}$ & No. & $\begin{array}{c}\text { The } \\
\text { correlation } \\
\text { coefficient }\end{array}$ & No. & $\begin{array}{c}\text { The } \\
\text { correlation } \\
\text { coefficient }\end{array}$ & No. & $\begin{array}{c}\text { The } \\
\text { correlation } \\
\text { coefficient }\end{array}$ & No. & $\begin{array}{c}\text { The } \\
\text { correlation } \\
\text { coefficient }\end{array}$ & No. & $\begin{array}{c}\text { The } \\
\text { correlation } \\
\text { coefficient }\end{array}$ & No. & $\begin{array}{l}\text { The } \\
\text { correlation } \\
\text { coefficient }\end{array}$ \\
\hline 1 & $0.2541 * *$ & 5 & $0.4593^{* *}$ & 9 & $0.2293^{* *}$ & 13 & $0.4356^{* *}$ & 17 & $0.2267^{* *}$ & 21 & $0.4877^{* *}$ & 25 & $0.4098 * *$ & 29 & $0.4091^{* *}$ \\
\hline 2 & $0.2226 * *$ & 6 & $0.2851^{* *}$ & 10 & $0.2313^{* *}$ & 14 & $0.2428 * *$ & 18 & $0.4162^{* *}$ & 22 & $0.2943^{* *}$ & 26 & $0.4939 * *$ & 30 & $0.1672^{*}$ \\
\hline 3 & $0.3045^{* *}$ & 7 & $0.3555^{* *}$ & 11 & $0.1831^{* *}$ & 15 & $0.2578 * *$ & 19 & $0.3954^{* *}$ & 23 & $0.3531^{* *}$ & 27 & $0.4138 * *$ & 31 & $0.2444^{* *}$ \\
\hline 4 & $0.2806^{* *}$ & 8 & $0.5514^{* *}$ & 12 & $0.1775^{*}$ & 16 & $0.2277^{* *}$ & 20 & $0.4588 * *$ & 24 & $0.3084^{* *}$ & 28 & $0.4193^{* *}$ & 32 & $0.4922 * *$ \\
\hline
\end{tabular}

*Correlation is significant at the 0.05 level (2-tailed). ${ }^{* *}$ Correlation is significant at the 0.01 level (2-tailed). 
Third: Pearson correlation coefficients between the total score of the dimensions of the survey with the total score of the survey:

\section{Reliability}

To examine the harmony of questionnaire statements, the Cronbach's alpha coefficient was used to calculate the internal consistency of patient safety dimensions. The Cronbach's alpha for these dimensions is (0.75). This result indicates that the reliability coefficient for all dimensions is not less than (0.60). This also means that the study is consistent and valid for the purposes of statistical analysis and scientific research.

\section{Statistical Methods Used}

The following statistical methods were used for statement attributes of the study sample and for examining the questions of the study: frequencies, percentages, means, standard deviation, pearson correlation coefficients, the Cronbach's alpha coefficient, and One Way Analysis of Variance.
Table 4: The correlation coefficients between the total score of the dimensions of the survey with the total score of the survey

\begin{tabular}{lc}
\hline \multicolumn{1}{c}{ The dimensions } & $\begin{array}{c}\text { The correlation } \\
\text { coefficient }\end{array}$ \\
\hline Teamwork Within Units & $0.3051^{* *}$ \\
\hline Teamwork Across Units & $0.6253^{* *}$ \\
\hline $\begin{array}{l}\text { Manager Expectations Actions Promot- } \\
\text { ing Patient Safety }\end{array}$ & $0.6687^{* *}$ \\
\hline $\begin{array}{l}\text { Organizational Learning Continuous Im- } \\
\text { provement }\end{array}$ & $0.2763^{* *}$ \\
\hline Management Support for Patient Safety & $0.4654^{* *}$ \\
\hline Feedback \& Communication of Error & $0.2892^{* *}$ \\
\hline Communication Openness & $0.5650^{* *}$ \\
\hline Frequency of Events Reported & $0.5004^{* *}$ \\
\hline Staffing & $0.5652^{* *}$ \\
\hline Handoffs \& Transitions & $0.5010^{* *}$ \\
\hline Non-punitive Response to Errors & $0.4316^{* *}$ \\
\hline Overall Perceptions of Patient Safety & $0.5926^{* *}$ \\
\hline * Correlation is significant at the 0.05 level (2-tailed). & \\
significant at the 0.01 level (2-tailed). &
\end{tabular}

\section{Limitations of the Study}

As is the case with other research studies, the design of the current study is subject to a numbers of limitations that need to be considered. First, this study is a pioneer investigation in the patient safety in KKUH, Saudi Arabia. Thus, further research is needed to assess the validity of the findings in a wider context. Second, this study was applied in Riyadh city because (1) the majority of the hospitals are located in this city (2) constraints of time in data collection and the limitation of financial resources. It is difficult to cover the vast area of Saudi Arabia. Hence the results can only be generalized with caution.

\section{Ethical Considerations}

The present study was subject to some ethical issues. All participants reported their acceptance regarding their participation in the study. At the same time, they were free to withdraw from it at any time without any reason. Next to this participants were informed of the purpose of the study, their names will be revealed in the study. Also, they were promised that their responses will not be seen by their employers and will be used for the purpose of scientific study only.

\section{Data analysis and discussion}

This section relates the findings obtained from the main instrument of this study, namely the quantitative analysis of the data collected from the questionnaire. This section is structured into two main parts. The first part is the section that analyses the sample of the study. The second section touches on the testing of the questions with interpretation of results.

\section{The sample of the study}

The sample of the study consists of (199) nurses from both genders who work in KKUH. Table 5. shows distributing the individuals of the sample ac-

Table 5: Distributing the individuals of the sample according to variable of gender

\begin{tabular}{|c|c|c|}
\hline Gender & Frequency & Percentage \\
\hline Male & 138 & $69 \%$ \\
\hline Female & 62 & $31 \%$ \\
\hline Total & 200 & $100 \%$ \\
\hline
\end{tabular}


cording to the variable of gender. Table 5. also shows that number of males was (138) and the percentage was (69\%), whereas the number of females was (62) and the percentage was (31\%).

Table 6. shows the percentage for distributing the individuals of the study according to variable of age. The highest percentage was $(41 \%)$ for the category (30-40) years. Whereas the lowest percentage was (1\%) for the category (61 years and above) years.

Table 7. shows the percentage for distributing the individuals of the study according to variable of years of experience. The highest percentage was (38.57\%) for the category (from 11 to less than 15 years). Whereas the lowest percentage was (6\%) for the category (less than 5 years) years.

Table 8. shows the percentage for distributing the individuals of the study according to variable of educational qualification. The highest percentage was (43\%) for the category (postgraduate study). Whereas the lowest percentage was (5.5\%) for the category (high school or less).

\section{Examining the Questions of the Study}

This section examines the proposed questions. One Way Analysis of Variance was adapted for testing the questions.

\section{The first question: What are the nurses' overall percep- tions of patient safety culture?}

To answer this question, descriptive statistics (mean, standard deviation and rank) were used to describe the nurses' perceptions of patient safety culture.
Table 6: Distributing the individuals of the sample according to the variable of age

\begin{tabular}{ccc}
\hline Age & Frequency & Percentage \\
\hline Less than 30 years & 28 & $14 \%$ \\
\hline From 30 to less than 40 & 82 & $41 \%$ \\
\hline From 40 to less than 50 & 57 & $28.5 \%$ \\
\hline From 50 to less than 60 & 31 & $15.1 \%$ \\
\hline 61 years and above & 2 & $1 \%$ \\
\hline Total & 200 & $100 \%$ \\
\hline
\end{tabular}

Table 7 Distributing the individuals of the study according to years of experience

\begin{tabular}{lcc}
\hline \multicolumn{1}{c}{ Years of experience } & Frequency & Percentage \\
\hline Less than 5 years & 12 & $6 \%$ \\
\hline From 5 to less than 10 years & 38 & $19 \%$ \\
\hline From 11 to less than 15 years & 77 & $38.5 . \%$ \\
\hline From 16 to less than 20 years & 53 & $26.5 \%$ \\
\hline 21 years and more & 20 & $10 \%$ \\
\hline Total & 200 & $100 \%$ \\
\hline
\end{tabular}

Table 8 Distributing the individuals of the study according to educational qualification

\begin{tabular}{|c|c|c|}
\hline Educational qualific & quer & Percentage \\
\hline High school or less & 11 & $5.5 \%$ \\
\hline Diploma & 25 & $12.5 \%$ \\
\hline Bachelor & 78 & $37 \%$ \\
\hline Postgraduate study & 86 & $43 \%$ \\
\hline Total & 200 & $100 \%$ \\
\hline
\end{tabular}

Table 9. shows the top three positive responses subscales are: teamwork within units (4.30), feedback and communication of error (4.04), organizational learning and continuous improvement (4.00). The lowest three positive responses subscales are: handoffs and transition (2.37), non-punitive response to errors (3.06), staffing (3.24).

These results can be explained asfollows:

a- There is cooperation and respect among the hospital staff that created a desire to work as a team to achieve the goals of the hospital as a whole and the division in which they
Table 9 Mean and standard deviation of nurses' responses on the patient safety culture dimensions

\begin{tabular}{lccc}
\hline \multicolumn{1}{c}{ Dimensions } & Mean & $\begin{array}{c}\text { Std. } \\
\text { Deviation }\end{array}$ & Rank \\
\hline Teamwork within units & 4.30 & 0.60 & 1 \\
\hline Teamwork across units & 3.46 & 0.57 & 8 \\
\hline Manager's expectations actions promoting patient safety & 3.49 & 0.61 & 7 \\
\hline Organizational learning continuous improvement & 4.00 & 0.58 & 3 \\
\hline Management support for patient safety & 3.61 & 0.58 & 5 \\
\hline Feedback and communication of error & 4.04 & 0.59 & 2 \\
\hline Communication openness & 3.44 & 0.53 & 9 \\
\hline Frequency of events reported & 3.74 & 0.64 & 4 \\
\hline Staffing & 3.24 & 0.66 & 10 \\
\hline Handoffs and transitions & 2.37 & 0.90 & 12 \\
\hline Non-punitive response to errors & 3.06 & 1.09 & 11 \\
\hline Overall perceptions of patient safety & 3.50 & 0.55 & 6 \\
\hline \multicolumn{1}{c}{ The total score } & 3.50 & 0.32 & \\
\hline
\end{tabular}

Source: from the results of statistical analysis. 
work. This cooperation has resulted in a support culture in which they all collaborate to finish work if there is too much work but too little time.

b- Information is shared with concerned staff about accidents and medical errors that might happen in the work environment. Additionally, there is an opportunity for discussing ways to prevent such errors from happening again.

c- It is noted that there are efforts made by the (KKUH) to evaluate quality and implement constant improvement for the patients' safety based on potential accidents and medical errors. The officials understand that such errors could lead to positive change within the hospital.

d- It seems that staff complaints in this area is due to insufficient staffing, which does not allow for executing the tasks optimally, nor does it facilitate patient care, quality assurance or efficiency.

e- The trans-section information exchange is deficient in the case of transferring patients from section to section or to other parties, or during shifts.

f- The KKUH administration seems to offer a non-punitive response to medical errors or staff mistakes, which might recur threatening the safety or life of the patients.

The second question: Is there a significant differences between the nurse's perception of patient safety culture and demographic characteristics?

To answer this question, descriptive statistics (frequency and percentage) were used to describe the event reports.

\section{Gender}

Table 10. shows the values of $(T)$ is non-significant in all dimensions of patient safety culture, which indicates that there was no statistically significant differences between the male and female in their perception of patient safety culture in those dimensions.

This result can be explained as follows: it seems that the male and female participants in the study at KKUH had the same point of view of the culture of patient safety.

\section{Education Level}

Table 11. shows the values of (F) is non-significant in dimensions: (teamwork within units, Manager's expectations actions promoting patient safety, organizational learning continuous improvement, management support for patient safety, feedback and communication of error, communication openness, staffing, handoffs

Table 10: T-test for the difference between the nurses perception of patient safety culture by gender

\begin{tabular}{|c|c|c|c|c|c|c|}
\hline Dimensions & Gender & $\mathrm{N}$ & Mean & $\begin{array}{c}\text { Std. } \\
\text { Deviation }\end{array}$ & T-value & Sig. \\
\hline \multirow{2}{*}{ Teamwork within units } & Male & 30 & 4.46 & 0.71 & \multirow{2}{*}{1.59} & \multirow{2}{*}{$\begin{array}{l}0.112 \\
\text { (N. S.) }\end{array}$} \\
\hline & Female & 169 & 4.27 & 0.57 & & \\
\hline \multirow{2}{*}{ Teamwork across units } & Male & 30 & 3.37 & 0.56 & \multirow{2}{*}{0.94} & \multirow{2}{*}{$\begin{array}{l}0.346 \\
\text { (N. S.) }\end{array}$} \\
\hline & Female & 169 & 3.47 & 0.57 & & \\
\hline \multirow{2}{*}{$\begin{array}{l}\text { Manager expectations actions } \\
\text { promoting patient safety }\end{array}$} & Male & 30 & 3.50 & 0.44 & \multirow{2}{*}{0.18} & \multirow{2}{*}{$\begin{array}{l}0.858 \\
\text { (N. S.) }\end{array}$} \\
\hline & Female & 169 & 3.48 & 0.64 & & \\
\hline \multirow{2}{*}{$\begin{array}{l}\text { Organizational learning con- } \\
\text { tinuous improvement }\end{array}$} & Male & 30 & 4.05 & 0.48 & \multirow{2}{*}{0.54} & \multirow{2}{*}{$\begin{array}{l}0.592 \\
\text { (N. S.) }\end{array}$} \\
\hline & Female & 169 & 3.99 & 0.60 & & \\
\hline \multirow{2}{*}{$\begin{array}{l}\text { Management support for } \\
\text { patient safety }\end{array}$} & Male & 30 & 3.68 & 0.51 & \multirow{2}{*}{0.68} & \multirow{2}{*}{$\begin{array}{l}0.497 \\
\text { (N. S.) }\end{array}$} \\
\hline & Female & 169 & 3.60 & 0.59 & & \\
\hline \multirow{2}{*}{$\begin{array}{l}\text { Feedback and communica- } \\
\text { tion of error }\end{array}$} & Male & 30 & 4.10 & 0.72 & \multirow{2}{*}{0.58} & \multirow{2}{*}{$\begin{array}{l}0.564 \\
\text { (N. S.) }\end{array}$} \\
\hline & Female & 169 & 4.03 & 0.56 & & \\
\hline \multirow{2}{*}{ Communication openness } & Male & 30 & 3.41 & 0.62 & \multirow{2}{*}{0.29} & \multirow{2}{*}{$\begin{array}{l}0.769 \\
\text { (N. S.) }\end{array}$} \\
\hline & Female & 169 & 3.44 & 0.51 & & \\
\hline \multirow{2}{*}{ Frequency of events reported } & Male & 30 & 3.69 & 0.62 & \multirow{2}{*}{0.45} & \multirow{2}{*}{$\begin{array}{l}0.654 \\
\text { (N. S.) }\end{array}$} \\
\hline & Female & 169 & 3.75 & 0.64 & & \\
\hline \multirow{2}{*}{ Staffing } & Male & 30 & 3.20 & 0.66 & \multirow{2}{*}{0.34} & \multirow{2}{*}{$\begin{array}{l}0.734 \\
\text { (N. S.) }\end{array}$} \\
\hline & Female & 169 & 3.24 & 0.66 & & \\
\hline \multirow{2}{*}{ Handoffs and transitions } & Male & 30 & 2.30 & 1.09 & \multirow{2}{*}{0.45} & \multirow{2}{*}{$\begin{array}{l}0.654 \\
\text { (N.S.) }\end{array}$} \\
\hline & Female & 169 & 2.38 & 0.87 & & \\
\hline \multirow{2}{*}{$\begin{array}{l}\text { Non-punitive response to } \\
\text { errors }\end{array}$} & Male & 30 & 3.12 & 1.34 & \multirow{2}{*}{0.25} & 0.806 \\
\hline & Female & 169 & 3.05 & 1.04 & & (N.S.) \\
\hline Overall perceptions of patient & Male & 30 & 3.67 & 0.61 & & 0.069 \\
\hline & Female & 169 & 3.47 & 0.53 & & (N. S.) \\
\hline & Male & 30 & 3.53 & 0.34 & & 0.631 \\
\hline & Female & 169 & 3.50 & 0.31 & 0.48 & (N. S.) \\
\hline
\end{tabular}

Source: from the results of statistical analysis. 
and transitions, overall perceptions of patient safety), which indicates that there was no statistically significant differences between the nurses' perception of patient safety culture in those dimensions attributable to the different in their education level.

Also shown in table 11., the values of (F) significant at 0.05 or less in dimensions: (teamwork across units, frequency of events reported, non-punitive response to errors), and in the total score of patient safety culture, which indicates that there was statistically significant differences between the Nurses' perception of patient safety culture in those dimensions attributable to the different in their education level. And by using the Scheffe test to determine the source of those differences (table 12):

Table 12. shows that there are significant differences at the $0.05 \mathrm{lev}$ el as follows:

- There are differences in dimension: teamwork across units between the sample with education level (bachelor) and between the samples with education level (high diploma) in favor of the sample with education level (high diploma).

- There are differences in dimension: frequency of events reported between the sample with education level (bachelor) and between the samples with education level (high diploma) in favor of the sample with education level (high diploma).

- There are differences in dimension: non-punitive response to errors between the sample with education level (bachelor) and between the samples with education level (post graduate) in favor of the sample with education level (post graduate).

- There are differences in the total score of patient safety culture between the sample with educa-
Table 11: One Way Analysis of Variance (F-test) for the difference between the nurses' perception of patient safety culture by different the education level

\begin{tabular}{|c|c|c|c|c|c|c|}
\hline Dime & Source & $\begin{array}{l}\text { Sum of } \\
\text { Squares }\end{array}$ & df & $\begin{array}{l}\text { Mean } \\
\text { Square }\end{array}$ & $\mathrm{F}$ & Sig. \\
\hline \multirow{2}{*}{ eamwork within units } & etween Groups & 0.15 & 2 & 0.08 & \multirow{2}{*}{0.21} & \multirow{2}{*}{$\begin{array}{l}0.811 \\
\text { (N. S.) }\end{array}$} \\
\hline & Within Groups & 70.02 & 196 & 0.36 & & \\
\hline \multirow{2}{*}{ Teamwork across units } & Between Groups & 3.18 & 2 & 1.59 & \multirow{2}{*}{-5.09} & \multirow{2}{*}{$\begin{array}{l}0.007 \\
(0.01)\end{array}$} \\
\hline & Within & 61.21 & 196 & 0.31 & & \\
\hline \multirow{2}{*}{$\begin{array}{l}\text { Manager's expectations } \\
\text { actions promoting } \\
\text { patient safety }\end{array}$} & Between Groups & 1.16 & 2 & 0.58 & \multirow{2}{*}{1.57} & \multirow{2}{*}{$\begin{array}{l}0.210 \\
\text { (N. S.) }\end{array}$} \\
\hline & Within & 72.33 & 196 & 0.37 & & \\
\hline \multirow{2}{*}{$\begin{array}{l}\text { Organizational learning } \\
\text { continuous improvement }\end{array}$} & Between Groups & 0.48 & 2 & 0.24 & \multirow{2}{*}{0.71} & \multirow{2}{*}{$\begin{array}{l}0.492 \\
\text { (N. S.) }\end{array}$} \\
\hline & Within Groups & 66.27 & 196 & 0.34 & & \\
\hline \multirow{2}{*}{$\begin{array}{l}\text { Management support } \\
\text { for patient safety }\end{array}$} & Between Groups & 0.06 & 2 & 0.03 & \multirow{2}{*}{0.09} & \multirow{2}{*}{$\begin{array}{l}0.912 \\
\text { (N. S.) }\end{array}$} \\
\hline & Within Groups & 66.33 & 196 & 0.34 & & \\
\hline \multirow{2}{*}{$\begin{array}{l}\text { Feedback and commu- } \\
\text { nication of error }\end{array}$} & Between Groups & 0.79 & 2 & 0.40 & \multirow{2}{*}{-1.15} & \multirow{2}{*}{$\begin{array}{l}0.319 \\
\text { (N.S.) }\end{array}$} \\
\hline & Within Groups & 67.59 & 196 & 0.35 & & \\
\hline \multirow{2}{*}{$\begin{array}{l}\text { Communication open- } \\
\text { ness }\end{array}$} & Between Groups & 0.15 & 2 & 0.07 & \multirow{2}{*}{0.26} & \multirow{2}{*}{$\begin{array}{l}0.770 \\
\text { (N. S.) }\end{array}$} \\
\hline & Within Groups & 54.82 & 196 & 0.28 & & \\
\hline \multirow{2}{*}{$\begin{array}{l}\text { Frequency of events } \\
\text { reported }\end{array}$} & Between Groups & 2.40 & 2 & 1.20 & \multirow{2}{*}{-3.02} & \multirow{2}{*}{$\begin{array}{l}0.051 \\
(0.05)\end{array}$} \\
\hline & Within Groups & 77.73 & 196 & 0.40 & & \\
\hline \multirow{2}{*}{ Staffing } & Between Groups & 1.57 & 2 & 0.78 & \multirow{2}{*}{-1.82} & \multirow{2}{*}{$\begin{array}{l}0.165 \\
\text { (N. S.) }\end{array}$} \\
\hline & Within Groups & 84.51 & 196 & 0.43 & & \\
\hline \multirow{2}{*}{ Handoffs and transitions } & Between Groups & 3.81 & 2 & 1.90 & \multirow{2}{*}{-2.36} & \multirow{2}{*}{$\begin{array}{l}0.097 \\
\text { (N. S.) }\end{array}$} \\
\hline & Within Groups & 158.06 & 196 & 0.81 & & \\
\hline \multirow{2}{*}{$\begin{array}{l}\text { Non-punitive response } \\
\text { to errors }\end{array}$} & Between Groups & 13.22 & 2 & 6.61 & \multirow{2}{*}{5.87} & 0.003 \\
\hline & Within Groups & 220.75 & 196 & 1.13 & & $(0.01)$ \\
\hline Overall perception & Between Groups & 1.50 & 2 & 0.75 & & 0.082 \\
\hline & Within Groups & 58.03 & 196 & 0.30 & & (N. S.) \\
\hline & Between Groups & 0.93 & 2 & 0.46 & & 0.010 \\
\hline & Within Groups & 19.14 & 196 & 0.10 & & $(0.01)$ \\
\hline
\end{tabular}

Source: from the results of statistical analysis.
Table 12: Multiple Range Tests: Scheffe test for the difference in participant's opinion by different the education level

\begin{tabular}{llllll}
\hline \multicolumn{1}{c}{ Dimensions } & Education level & Mean & Bachelor & In favor of \\
\hline Teamwork across units & High Diploma & 3.64 & $*$ & High Diploma \\
\hline Frequency of events reported & High Diploma & 3.86 & $*$ & High Diploma \\
\hline Non-punitive response to errors & Post Graduate & 4.17 & $*$ & Post Graduate \\
\hline \multicolumn{2}{c}{ The total score } & High Diploma & 3.59 & $*$ & High Diploma \\
\hline
\end{tabular}

Source: from the results of statistical analysis.

$(*)$ Indicates significant differences which are shown in the table. $\quad\left(^{*}\right)$ The mean difference is significant at the .050 level. 
tion level (bachelor) and between the samples with education level (high diploma) for the benefit of members of the sample with education level (high diploma).

These results can be explained as follows: It is evident that staff with high qualifications have a desire for team work and realize the importance of documenting medical errors. Also, they understand that non-punitive reaction to medical errors has a direct negative impact on the patient's life and safety.

\section{Age}

Table 13. shows that the values of $(f)$ is non-significant in dimensions: (teamwork within units, teamwork across units, manager's expectations actions promoting patient safety, management support for patient safety, communication openness, frequency of events reported, staffing, non-punitive response to errors, overall perceptions of patient safety), and in the total score of patient safety culture, which indicates that there was no statistically significant differences between the nurses perception of patient safety culture in those dimensions attributable to the different in their age.

Also shown in table 13 that the values of ( $f$ ) significant at 0.01 in dimensions: (organizational learning continuous improvement, feedback and communication of error, handoffs and transitions), which indicates that there was statistically significant differences between the nurses perception of patient safety culture in those dimensions attributable to the different in their age. By using the Scheffe test to determine the source of those differences (table 14).

Table 14 shows that there are significant differences at the 0.05 level as follows:

- There are differences in dimension: organizational learning continuous improvement between the
Table 13: One Way Analysis of Variance (F-test) for the difference between the nurses' perception of patient safety culture according to their

\begin{tabular}{|c|c|c|c|c|c|c|}
\hline Dim & S & $\begin{array}{l}\text { Sum of } \\
\text { Squares }\end{array}$ & df & $\begin{array}{c}\text { Mean } \\
\text { Square } \\
\end{array}$ & $\mathbf{F}$ & Sig. \\
\hline \multirow{2}{*}{ Teamwork within units } & Betw & 0.24 & 2 & 0.12 & \multirow{2}{*}{0.34} & \multirow{2}{*}{$\begin{array}{l}0.715 \\
\text { (N.S.) }\end{array}$} \\
\hline & Withir & 69.93 & 196 & 0.36 & & \\
\hline \multirow{2}{*}{ Teamwork across units } & Betwe & 0.91 & 2 & 0.46 & \multirow{2}{*}{-1.41} & \multirow{2}{*}{$\begin{array}{l}0.247 \\
\text { (N. S.) }\end{array}$} \\
\hline & Withi & 63.47 & 196 & 0.32 & & \\
\hline \multirow{2}{*}{$\begin{array}{c}\text { Manager's expectations } \\
\text { actions promoting } \\
\text { patient safety }\end{array}$} & Betwe & 0.14 & 2 & 0.07 & \multirow{2}{*}{0.19} & \multirow{2}{*}{$\begin{array}{l}0.829 \\
\text { (N. S.) }\end{array}$} \\
\hline & Withi & 73.35 & 196 & 0.37 & & \\
\hline \multirow{2}{*}{$\begin{array}{c}\text { Organizational learning } \\
\text { continuous improve- } \\
\text { ment }\end{array}$} & Bet & 3.07 & 2 & 1.54 & \multirow{2}{*}{4.73} & \multirow{2}{*}{$\begin{array}{l}0.010 \\
(0.01)\end{array}$} \\
\hline & Withi & 63.68 & 196 & 0.33 & & \\
\hline \multirow{2}{*}{$\begin{array}{c}\text { Management support } \\
\text { for patient safety }\end{array}$} & Betwee & 0.47 & 2 & 0.24 & \multirow{2}{*}{0.70} & \multirow{2}{*}{$\begin{array}{l}0.497 \\
\text { (N. S.) }\end{array}$} \\
\hline & Withi & 65.92 & 196 & 0.34 & & \\
\hline \multirow{2}{*}{$\begin{array}{c}\text { Feedback and commu- } \\
\text { nication of error }\end{array}$} & Between Groups & 3.71 & 2 & 1.85 & \multirow{2}{*}{5.62} & \multirow{2}{*}{$\begin{array}{l}0.004 \\
(0.01) \\
\end{array}$} \\
\hline & Withi & 64.68 & 196 & 0.33 & & \\
\hline \multirow{2}{*}{$\begin{array}{c}\text { Communication open- } \\
\text { ness }\end{array}$} & Betwee & 0.26 & 2 & 0.13 & \multirow{2}{*}{-0.46} & \multirow{2}{*}{$\begin{array}{l}0.633 \\
(\text { N. S.) }\end{array}$} \\
\hline & With & 54.71 & 196 & 0.28 & & \\
\hline \multirow{2}{*}{$\begin{array}{c}\text { Frequency of events } \\
\text { reported }\end{array}$} & Betwe & 0.40 & 2 & 0.20 & \multirow{2}{*}{0.49} & \multirow{2}{*}{$\begin{array}{l}0.611 \\
(\mathrm{~N} . \mathrm{S} .)\end{array}$} \\
\hline & Witl & 79.73 & 196 & 0.41 & & \\
\hline \multirow{2}{*}{ Staffing } & Betwe & 0.32 & 2 & 0.16 & \multirow{2}{*}{0.37} & \multirow{2}{*}{$\begin{array}{l}0.694 \\
\text { (N. S.) }\end{array}$} \\
\hline & With & 85.76 & 196 & 0.44 & & \\
\hline \multirow{2}{*}{ Handoffs and transitions } & Between Groups & 6.87 & 2 & 3.43 & \multirow{2}{*}{-4.34} & \multirow{2}{*}{$\begin{array}{l}0.014 \\
(0.01) \\
\end{array}$} \\
\hline & Within Groups & 155.00 & 196 & 0.79 & & \\
\hline \multirow{2}{*}{$\begin{array}{c}\text { Non-punitive response } \\
\text { to errors }\end{array}$} & Between Groups & 2.41 & 2 & 1.20 & \multirow{2}{*}{-1.02} & 0.363 \\
\hline & Within Groups & 231.56 & 196 & 1.18 & & (N.S.) \\
\hline Overall perceptions of & Between Groups & 0.88 & 2 & 0.44 & & 0.231 \\
\hline & Within Groups & 58.64 & 196 & 0.30 & & (N.S.) \\
\hline & Between Groups & 0.11 & 2 & 0.06 & & 0.575 \\
\hline & Within Groups & 19.95 & 196 & 0.10 & & \\
\hline
\end{tabular}

Source: from the results of statistical analysis.
Table 14: Multiple range tests: Scheffe test for the difference in participant's opinion according to their age

\begin{tabular}{lcccccc}
\hline \multicolumn{1}{c}{ Dimensions } & Age & Mean & $\begin{array}{c}\text { Below } \\
\text { 30 Years }\end{array}$ & $\begin{array}{c}30-40 \\
\text { Years }\end{array}$ & $\begin{array}{c}\text { Over } 40 \\
\text { Years }\end{array}$ & In favor of \\
\hline $\begin{array}{l}\text { Organizational learning } \\
\text { continuous improvement }\end{array}$ & $\begin{array}{c}\text { Below 30 } \\
\text { Years }\end{array}$ & 4.23 & $*$ & $*$ & $\begin{array}{c}\text { Below } 30 \\
\text { Years }\end{array}$ \\
\hline $\begin{array}{l}\text { Feedback and communi- } \\
\text { cation of error }\end{array}$ & $\begin{array}{c}\text { Below 30 } \\
\text { Years }\end{array}$ & 4.30 & & $*$ & $*$ & $\begin{array}{c}\text { Below } 30 \\
\text { Years }\end{array}$ \\
\hline $\begin{array}{l}\text { Handoffs and transitions } \\
\text { 30-40 Years }\end{array}$ & 2.51 & $*$ & & $30-40$ Years \\
\hline $\begin{array}{l}(*) \text { Indicates significant differences which are shown in the table. } \\
\text { significant at the .050 level. }\end{array}$
\end{tabular}


sample with age (30-40 years, over 40 years) and between the samples with age (below 30 years) in favor of the sample with age (below 30 years).

- There are differences in dimension: feedback and communication of error between the sample with age (30-40 years, over 40 years) and between the samples with age (below 30 years) in favor of the sample with age (below 30 years).

- There are differences in dimension: handoffs and transitions between the sample with age (below 30 years) and between the samples with age (30-40 years) in favor of the sample with age (30-40 years).

These results can be explained as follows: It is evident that young staff have a serious desire to continuously learn about the culture of patient safety and also knowing potential medical errors in work environment and how to deal with them.
Table 15: One Way Analysis of Variance (F-test) for the difference between the nurses' perception of patient safety culture according to different Years of experience

\begin{tabular}{|c|c|c|c|c|c|c|}
\hline 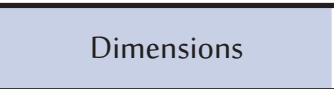 & Source & $\begin{array}{l}\text { Sum of } \\
\text { Squares }\end{array}$ & $\mathrm{df}$ & $\begin{array}{l}\text { Mean } \\
\text { Square }\end{array}$ & $\mathrm{F}$ & Sig. \\
\hline \multirow{2}{*}{ eamwo } & s & 0.07 & 3 & 0.02 & \multirow{2}{*}{0.07} & \multirow{2}{*}{$\begin{array}{l}0.978 \\
\text { (N.S. }\end{array}$} \\
\hline & Within & 70.10 & 195 & 0.36 & & \\
\hline \multirow{2}{*}{ Teamwork across units } & Betwe & 4.58 & 3 & 1.53 & \multirow{2}{*}{-4.98} & \multirow{2}{*}{$\begin{array}{l}0.002 \\
(0.01\end{array}$} \\
\hline & Withir & 59.81 & 195 & 0.31 & & \\
\hline \multirow{2}{*}{$\begin{array}{l}\text { Manager expectations } \\
\text { actions promoting pa- } \\
\text { tient safety }\end{array}$} & ps & 2.41 & 3 & 0.80 & \multirow{2}{*}{2.20} & \multirow{2}{*}{$\begin{array}{l}0.089 \\
(\text { N. S.) }\end{array}$} \\
\hline & Witl & 71.08 & 195 & 0.37 & & \\
\hline \multirow{2}{*}{$\begin{array}{l}\text { Organizational learning } \\
\text { continuous improvement }\end{array}$} & B & 2.53 & 3 & 4 & \multirow{2}{*}{-2.56} & \multirow{2}{*}{$\begin{array}{l}0.056 \\
\text { (N.S.) }\end{array}$} \\
\hline & With & 64.22 & 195 & 0.33 & & \\
\hline \multirow{2}{*}{$\begin{array}{l}\text { Management support for } \\
\text { patient safety }\end{array}$} & Betwee & 0.33 & 3 & 0.11 & \multirow{2}{*}{0.33} & \multirow{2}{*}{$\begin{array}{l}0.806 \\
\text { (N.S.) }\end{array}$} \\
\hline & With & 66.06 & 195 & 0.34 & & \\
\hline \multirow{2}{*}{$\begin{array}{l}\text { Feedback and communi- } \\
\text { cation of error }\end{array}$} & Betwee & 1.28 & 3 & 0.43 & \multirow{2}{*}{-1.24} & \multirow{2}{*}{$\begin{array}{l}0.298 \\
(\mathrm{~N} . \mathrm{S} .)\end{array}$} \\
\hline & Witł & $6 \% .17$ & 195 & 0.34 & & \\
\hline \multirow{2}{*}{$\begin{array}{l}\text { Communication open- } \\
\text { ness }\end{array}$} & Betw & 0.39 & 3 & 0.13 & \multirow{2}{*}{-0.47} & \multirow{2}{*}{$\begin{array}{l}0.707 \\
\text { (N.S.) }\end{array}$} \\
\hline & With & 54.57 & 195 & 0.28 & & \\
\hline \multirow{2}{*}{$\begin{array}{l}\text { Frequency of events } \\
\text { reported }\end{array}$} & Betwe & 3.83 & 3 & 1.28 & \multirow{2}{*}{-3.26} & \multirow{2}{*}{$\begin{array}{l}0.023 \\
(0.05)\end{array}$} \\
\hline & Within Groups & 76.30 & 195 & 0.39 & & \\
\hline \multirow{2}{*}{ Staffing } & Betw & 2.03 & 3 & 0.68 & \multirow{2}{*}{-1.57} & \multirow{2}{*}{$\begin{array}{l}0.198 \\
\text { (N.S.) }\end{array}$} \\
\hline & Wit & 84.05 & 195 & 0.43 & & \\
\hline \multirow{2}{*}{ Handoffs and transitions } & Betwee & 8.72 & 3 & 2.91 & \multirow{2}{*}{-3.70} & \multirow{2}{*}{$\begin{array}{l}0.013 \\
(0.01)\end{array}$} \\
\hline & With & 153.14 & 195 & 0.79 & & \\
\hline \multirow{2}{*}{$\begin{array}{l}\text { Non-punitive response } \\
\text { to errors }\end{array}$} & Between Groups & 7.07 & 3 & 2.36 & \multirow{2}{*}{-2.02} & 0.112 \\
\hline & Within & 226.90 & 195 & 1.16 & & (N. S.) \\
\hline & Between Groups & 3.92 & 3 & 1.31 & & 0.00 \\
\hline & Within Groups & 55.61 & 195 & 0.29 & & \\
\hline & Between Groups & 1.02 & 3 & 0.34 & & 0.01 \\
\hline & Within Groups & 19.04 & 195 & 0.10 & & \\
\hline
\end{tabular}

Source: from the results of statistical analysis.

\section{Years of experience}

Table 15. shows that the values of (f) are non-significant in dimensions: (teamwork within units, Manager's expectations actions promoting patient safety, organizational learning continuous improvement, management support for patient safety, feedback and communication of error, communication openness, staffing, non-punitive response to errors), which indicates that there was no statistically significant differences between the nurses' perception of patient safety culture in those dimensions attributable to the different in there years of experience.

Also shown in table 15. that the values of ( $f$ ) significant at 0.01 or less in dimensions: (teamwork across units, frequency of events reported, handoffs and transitions, overall perceptions of patient safety), and in the total score of patient safety culture, which indicates that there was statistically significant differences between the nurses' perception of patient safety culture in those dimensions attributable to the different years of experience. By using the Scheffe test to determine the source of those differences (table 16):

Table 16. shows that there are significant differences at the 0.05 level as follows: 
- There are differences in dimension: teamwork across units between the samples with years of experience (less than 1 year) and between the samples with years of experience (6 to 10 years) in favor of the sample with years of experience (6 to 10 years).

- There are differences in dimension: frequency of events reported between the samples with years of Table 16: Multiple range tests: Scheffe test for the difference in participant's opinion by different the years of experience

\begin{tabular}{|c|c|c|c|c|c|}
\hline Dimensions & $\begin{array}{c}\text { Years of } \\
\text { experience }\end{array}$ & Mean & $\begin{array}{l}\text { Less } \\
\text { than } 1 \\
\text { year }\end{array}$ & $\begin{array}{l}1 \text { to } 5 \\
\text { years }\end{array}$ & In favor of \\
\hline Teamwork across units & 6 to 10 years & 3.72 & $*$ & & 6 to 10 years \\
\hline Frequency of events reported & 6 to 10 years & 3.96 & & * & 6 to 10 years \\
\hline Handoffs and transitions & 6 to 10 years & 2.67 & $*$ & & 6 to 10 years \\
\hline $\begin{array}{l}\text { Overall perceptions of } \\
\text { patient safety }\end{array}$ & 6 to 10 years & 3.77 & $*$ & $*$ & 6 to 10 years \\
\hline The total score & 6 to 10 years & 3.64 & & * & 6 to 10 years \\
\hline
\end{tabular}
Source: from the results of statistical analysis.

${ }^{*}$ Indicates significant differences which are shown in the table. $\left.{ }^{*}\right)$ The mean difference is significant at the .050 level. experience ( 1 to 5 years) and between the samples with years of experience ( 6 to 10 years) in favor of the sample with years of experience (6 to 10 years).

- There are differences in dimension: handoffs and transitions between the samples with years of experience (less than 1 year) and between the samples with years of experience (6 to 10 years) in favor of the sample with years of experience (6 to 10 years).

- There are differences in dimension: overall perceptions of patient safety between the samples with years of experience (less than 1 year, 1 to 5 years) and between the samples with years of experience (6 to 10 years) in favor of the sample with years of experience (6 to 10 years).

- There are differences in the total score of patient safety culture between the samples with years of experience ( 1 to 5 years) and between the samples with years of experience (6 to 10 years) in favor of the sample with years of experience (6 to 10 years).

These results can be explained as follows: It is evident that staff with long experience have gained numerous benefits in this area such as encouraging team work, the belief in the significance of punitive response to medical errors. They understand the importance of exchanging information when transferring patients to different sections or departments.

\section{The third question: How many event reports have you filled out and submitted in the last year?}

To answer this question, descriptive statistics (frequency and percentage) were used to describe the event reports.

Table 17. shows the highest percentage is (64.3\%) in favor of (no event reports).

These results can be explained as follows: $64 \%$ of the study sample indicated the absence of any reports on medical errors. This can mean one of two things or both of them: a) there have been no medical errors; b) there have been medical errors, but there have not been reported in fear of punishment, accountability and possibly termination for the employee in question.

\section{Recommendations}

Holding training workshops on the culture of patient safety in general focusing on the definition, importance and prevention of medical errors connected to the patient's life and safety.

Table 17: Distribution of study sample according the number of event reports they have filled out and submitted

\begin{tabular}{|c|c|c|}
\hline Answer & Frequency & Percent \\
\hline No event reports & 128 & 64.3 \\
\hline 1 to 2 event reports & 63 & 31.7 \\
\hline 3 event reports or more & 8 & 4.0 \\
\hline Total & 199 & 100.0 \\
\hline
\end{tabular}


1- Conducting a periodical survey through the administration of KKUH to evaluate the culture of patient safety. The survey is to be distributed to the patients and beneficiaries to underscore the weaknesses and strengths in order to support positive practices and resolve negative situations.

2- Since the study results show that the response of the participants in regards to (handoffs and transitions) was low, the KKUH administration needs to work on facilitating the exchange of patient information between hospital units through finding the most appropriate ways to exchange information efficiently and smoothly.

3- Since the study results show that the response of the participants in regards to (staffing) was low, the KKUH administration should work on providing sufficient technical and administrative staff needed.

4- Since the study results show that the response of the participants in regards to (non-punitive response to errors) was low, the KKUH administration should develop a clear policy for how to deal with medical errors. The policy must include ways to avoid such errors and provide penalties for those involved in such errors, which could claim patients' lives.

5- Finally, the KKUH administration needs to see the importance of medical errors and how they could lead to positive changes in the work environment.

\section{Areas for further study}

The findings of this study did not cover comprehensively all factors of the patient safety culture in the Saudi Arabia. The study provides other areas for the further research including:

- The patient safety culture: a public and private hospitals comparison in Saudi Arabia.

- The patient safety culture: Saudi and non-Saudi nurses comparison in Saudi Arabia. 


\section{References}

Aboshaiqah, A. (2010). «Patients Safety Culture: A Baseline Assessment of Nurses' Perceptions in a Saudi Arabia Hospital», Doctoral Unpublished Thesis, Wayne State University.

Alahmadi, H. (2010). «Assessment of Patient Safety Culture in Saudi», Quality Safety Health Care, 19 (5): e17. doi: 10.1136/qshc.2009.033258.

Al Doweri, H.; Al Raoush, A.; Al Khatib, A. and Batiha, M. (2015). «Patient Safety Culture: Principles and Applications: Review Article», European Scientific Journal, 11 (15): 83-94.

Al Jabri, D. (2012). «Assessment of Patient Safety Culture in Saudi Hospitals: A Baseline Study in the Eastern Region, JKAU:Med. Sci., 19 (1S): 43-85.

Alkorashy, H. A. (2013). «Factors Shaping Patient Safety Management in the Middle East Hospitals from Nursing Perspective: A Focus Group Study», Middle-East Journal of Scientific Research, 15 (10): 1375-1384.

- $\quad$ Bandura, A. (1978). The Self System in Reciprocal Determinism. The American Psychologist Association, Inc.

- Commission, H. (1993). ACSNI Study Group on Human Factors. London: $3^{\text {rd }}$ Report: Organising for Safety.

Cooper, M. (2000). Towards a Model of Safety Culture. Elsevier Science Ltd, 36: 111-136.

Eldeeb, G.; Ghoneim, A. and Eldesouky, E. (2016). «Perception of Patient Safety Among Nurses at Teaching Hospital», American Journal of Nursing Science, 5 (4): 122-128.

Ghobashi, M.; El-Ragehy, H.; Mosleh, H. and Al-Doseri, F. (2014). «Assessment of Patient Safety Culture in Primary Health Care Settings in Kuwait", Epidemiology Biostatistics and Public Health, 11 (3): e9101-1 - e9101-9.

Helmreich, R. (2000). "Culture and Error in Space: Implications from Analog Environments", Aviation, Space, and Environmental Medicine, 71 (9-11): 133-139.

Hopkins, J. (2016). Medical Error: The Third Leading Cause of Death in the US. BMJ 2016; 353 doi: http://dx.doi.org/10.1136/bmj.i2139.

Institute of Medicine (IOM). (2004). Keeping Patients Safe: Transforming the Work Environment of Nurses. Washington, DC: National Academies Press.

Irfan, M. (Monday 3 February 2014). Medical Errors on the Rise. Arab News.

Kennedy, R. (1998). «Development of a Hazard and Operability: Based Method for Identifying Safety Management Vulnerabilities in High Risk Systems", Safety Science, 30: 240-274.

Mikušová, V.; Rusnakova, V.; Nadova, K.; Boronova, J. and Betkova, M. (2012). «Patient Safety Assessment in Slovak Hospitals", International Journal of Collaborative Research on Internal Medicine and Public Health, 4 (6): 1236-1244.

- Nieva, V. and Sorra, J. (2003). «Safety Culture Assessment: A Tool for Improving Patient Safety in Healthcare Organizations", Quality and Safety in Health Care, 12, 17-23.

Reason, J. (2000). Managing the Risks of Organizational Accidents. Aldershot: Ashgate.

Sagiroglu, T.; Oğuz, S.; Yağcı, M.; Tozkır, H. and Yalta, T. (2013). «Evaluation of Patient Safety Culture: Single-Center, Non-Randomized: Cross-Sectional study", Department of General Surgery, Faculty of Medicine, Trakya University, Turkey Experience. Scientific Research and Essays, 8 (10): 398-403.

The Agency for Healthcare Research and Quality (AHRQ). (2016). Available: www.ahrq.gov.

Verbakel, N.; Melle, M.; Langelaan, M.; Verheij, T.; Wagner, C. and Zwart, D. (2014). «Exploring Patient Safety Culture in Primary Care", International journal for Quality in Health Care, 26 (6): 585-591. DOI: http://dx.doi.org/10.1093/intqhc/mzu074.

- Wagner, C.; Smith, M.; Sorra, J. and Huang, C. (2013). «Assessing Patient Safety Culture in Hospitals Across Countries", International Journal for Quality in Health Care, 25 (3): 213-221. DOI: http://dx.doi.org/10.1093/intqhc/mzt024.

- Zhao, P.; Yaqin, L.; Li, Z.; Jia, P., Zhang, L. and Zhang, M. (2017). «Use of Patient Safety Culture Instruments in Operating Rooms: A Systematic Literature Review", Journal of Evidence-based Medicin, 10 (2): 145-151.

Zohar, D. (1980). "Safety Climate in Industrial Organizations: Theoretical and Applied Implications", Journal of Applied Psychology, 65 (1): 96-102. 


\section{Questionnaire}

\section{Demographic information:}

- Gender Male ( ) Female ( )

- Education Level

- Age Below 30

High Diploma ( ) Bachelor

( ) Post Graduate

Over 50( )

How long have you worked in your current hospital?

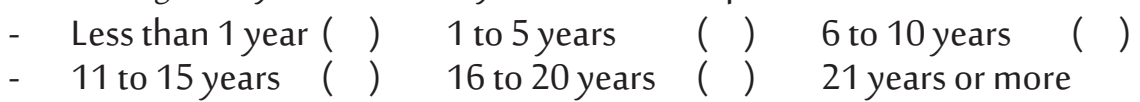

\begin{tabular}{|c|c|c|c|c|c|c|}
\hline Ser. & items & 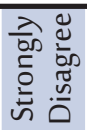 & 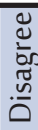 & $\frac{3}{3}$ & ه & 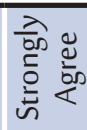 \\
\hline
\end{tabular}

Teamwork Within Units

1 People support one another in this unit

2 When a lot of work needs to be done quickly, we work together as a team to get the work done

3 In this unit, people treat each other with respect

Teamwork Across Units

4 There is good cooperation among hospital units that need to work together

5 It is often unpleasant to work with staff from other hospital units

Supervisor/Manager Expectations \& Actions Promoting Patient Safety

6 My supervisor/manager says a good word when he/she sees a job done according to established patient safety procedures

7 My supervisor/manager seriously considers staff suggestions for improving patient safety

8 Whenever pressure builds up, my supervisor/manager wants us to work faster, even if it means taking shortcuts

Organizational Learning-Continuous Improvement

9 Mistakes have led to positive changes here

10 After we make changes to improve patient safety, we evaluate their effectiveness

Management Support for Patient Safety

11 Hospital management provides a work climate that promotes patient safety

12 The actions of hospital management show that patient safety is a top priority

13 Hospital management seems interested in patient safety only after an adverse event happens

Feedback \& Communication About Error

14 We are given feedback about changes put into place based on event reports

15 In this unit, we discuss ways to prevent errors from happening again

Communication Openness

16 Staff will freely speak up if they see something that may negatively affect patient care

17 Staff feel free to question the decisions or actions of those with more authority

18 Staff are afraid to ask questions when something does not seem right Frequency of Events Reported

19 When a mistake is made, but is caught and corrected before affecting the patient, how often is this reported?

20 When a mistake is made, but has no potential to harm the patient, how often is this reported?

21 When a mistake is made that could harm the patient, but does not, how often is this reported? Staffing

22 We have enough staff to handle the workload

23 Staff in this unit work longer hours than is best for patient care

24 We work in "crisis mode" trying to do too much, too quickly 


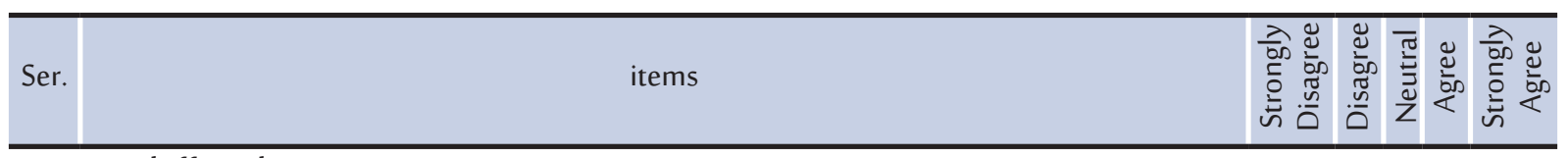

\section{Handoffs and Transitions}

25 Things «fall between the cracks" when transferring patients from one unit to another

26 Important patient care information is often lost during shift changes

27 Problems often occur in the exchange of information across hospital units

Non-punitive Response to Errors

28 Staff feel like their mistakes are held against them

29 When an event is reported, it feels like the person is being written up, not the problem

Overall Perceptions of Patient Safety

30 Patient safety is never sacrificed to get more work done

31 Our procedures and systems are good at preventing errors from happening

32 We have patient safety problems in this unit

33. Please give your work area/unit in this hospital an overall grade on patient safety.
A. Excellent
B. Very Good
C. Acceptable
D. Poor
E. Failing

34. In the past 12 months, how many event reports have you filled out and submitted?
A. No event reports
B. 1 to 2 event reports
C. 3 to 5 event reports
D. 6 to 10 event reports
E. 11 to 20 event reports
F. 21 event reports or more 